\title{
Shift From a Traditional to a Distance Learning Environment during the COVID-19 Pandemic
}

\section{University Students' Engagement and Interactions}

\author{
Katerina Salta ${ }^{1}$ (D) Katerina Paschalidou ${ }^{1}$ (D) Maria Tsetseri $^{2}$ (D) \\ Dionysios Koulougliotis ${ }^{3}$ (D)
}

Accepted: 14 April 2021 / Published online: 8 June 2021

(c) The Author(s), under exclusive licence to Springer Nature B.V. 2021

\begin{abstract}
The paper reports a study aimed at investigating tertiary education students' engagement and interactions in the traditional face-to-face learning environment and the sequentially applied distance online learning environment imposed by the sudden upsurge of a worldwide health emergency, the COVID-19 pandemic in Spring 2020. The study took place in four distinct science learning communities formed by a total of 347 undergraduate students attending three different academic majors (Chemistry, Environmental Science, and Food Science and Technology) and 13 postgraduate students attending a Masters program related to Chemistry Education, in two Greek universities. The majority of the measured variables were shown to depend on the institution, the academic major, and the semester of study, although to a varying degree. Data analysis provided evidence for a statistically significant lower level of emotional engagement in the online relative to the traditional learning environment among the students of all three undergraduate learning communities. Multiple regression analysis showed that this documented decrease in students' emotional engagement is largely explained by the concurrent decrease at the level of human interaction (either student-student or student-instructor) upon the passage from the traditional to the online learning environment.
\end{abstract}

Dionysios Koulougliotis

dkoul@ionio.gr

1 Department of Chemistry, National and Kapodistrian University of Athens, Panepistimiopolis Zografou, 157 84, Athens, Greece

2 Department of Physics, National and Kapodistrian University of Athens, Panepistimiopolis Zografou, 157 84, Athens, Greece

3 Department of Environment, Ionian University, M. Minotou-Giannopoulou, 29100 Zakynthos, Greece 


\section{Introduction}

The COVID-19 pandemic has influenced educational systems worldwide, leading to the temporary closures of schools and universities. Until August 2020, approximately 1.600 billion students were affected by school and higher education closures in response to the pandemic (United Nations, 2020). In order to overcome this problem, UNESCO recommended the use of distance learning environments (UNESCO, 2020). Therefore, the COVID-19 pandemic constituted a huge challenge to educators to urgently adapt all their classes to distance learning in order to maintain learning continuity with the same level of quality.

The shift from traditional classroom education to online distance education affects various aspects of educational practices (Al-Gahtani, 2016; Hong et al., 2017; Luo et al., 2017). In the online learning environment, instructors do not directly observe students' learning tasks, and students do not interact face to face with instructors and other students during learning activities. Consequently, the lack of physically social presence influences students' engagement and leads to the development of a sense of isolation, which is a key element for the high dropout rate of online learning (Luo et al., 2017; Rovai \& Barnum, 2003).

Student engagement has been conceptualized as a multifaceted construct that includes emotional, behavioral, and cognitional domains (Appleton et al., 2006; Fredricks et al., 2004). Affective components of engagement (emotional engagement) have been operationally associated with students' sense of community (Fredricks et al., 2004). The sense of community experienced by an individual has been established as a key factor to shorten the distance between people. An increasing body of research supports the significant role that students' level of engagement plays in their academic, social, and emotional adjustment to classrooms and school settings (Osterman, 2000). Finn \& Rock (1997) identified the lack of engagement in the school and classroom as an important factor for academic failure. Teachers' and peers' support within the classroom has been identified among the factors which influence engagement (Bateman, 2002).

Although the psychological perspective acknowledges internal factors that impact on engagement, the sociocultural perspective recognizes that learning involves the broader dynamic of students' interactions with peers, teachers, and diverse learning opportunities (Kahu, 2013). For online learning, it is essential to understand the ways with which these interactions affect students' engagement (Luo et al., 2017). Rovai (2002) argued that students' interactions constitute an essential element for developing a sense of community and emotional engagement. Recently, Jiang (2017) has argued that the sense of community can be best promoted by student-instructor and student-student interaction than by student-content interaction.

The framework of a learning community enables an investigation of learning through certain forms of interactions between community's members (i.e., the instructors and students as well as between students) and between the students and the educational tools. This is especially important for social distancing and self-isolation conditions because of the critical role that the members of a learning community play in organizing themselves for adapting to a pandemic. During March 2020, Greece was found in the center of the pandemic caused by the COVID-19 virus, which led to the adoption of various measures of social distancing and self-isolation. The application of a total lockdown as a social distancing measure led to an abrupt shift from the traditional face-to-face in-campus education to an online (synchronous or asynchronous) learning environment in all Greek Universities. 
Therefore, the purpose of this study is the investigation of how a shift from a traditional to an online (distance) educational environment affects students' interactions with the other members of a community as well as their engagement in each learning environment, by using the framework of communities of practice, as is a university-based science learning community. More specifically, the above-described investigation is deployed among the students of four science learning communities (three undergraduate and one post-graduate) enrolled in three academic departments of two Greek Universities. In addition to the students' interactions and engagement in the two learning environments (i.e., face to face and distance), the obstacles that students encountered during distance learning are investigated as well. The findings are expected to bring out important factors which influence the effectiveness of distance learning.

\section{Conceptual Framework}

\subsection{Community of Practice-Learning Community}

Learning is considered as a social process based on interactions within groups (Swan \& Shea, 2005; Vygotsky, 1986). The interactions among group members lead to the formation of community, the construction of knowledge, and student learning (Cobb, 1994; Vygotsky, 1986). The participation of all members (both students and instructors) plays a central role in the development and maintenance of any learning community.

An important task for science educators is to explicitly teach and engage students within the sociocultural practices of the discipline (Kelly, 2007; Leach \& Scott, 2003). However, investigating learning through this perspective requires a unit of analysis that is larger than an individual student. As an alternative, it calls for an expanded framework that captures an entire science learning community, which could be recognized as a community of practice (González-Howard \& McNeill, 2016).

A science learning community circumscribes the social and physical environment that provides context for participation. The community itself is constituted by the acting individuals, the tools, both conceptual and physical, used in community practices, and the cultural norms that guide practice and interactions within the community (Sadler, 2009). The boundaries of a community are defined by a central focus or aim. For example, learning communities in science education tend to coalesce around the teaching and learning of science.

Since the practices promoted in an academic department of a science discipline (or briefly a science department) are inherently sociocultural activities (Oliveira et al., 2012), their exploration requires looking into the different ways and circumstances under which students engage with science learning communities' practices (Leach \& Scott, 2003). We suggest that conceptualizing a science department as a learning community offers a powerful lens through which to explore the individuals' learning as they interact in the context of a science discipline.

The idea of the school or a science department as a learning community can be traced back to the works of Dewey (1938) and Vygotsky (1986) who claimed that the process of learning is facilitated through individual participation in social interactions. Thus, the learning tasks based on this social-constructivism perspective emphasize learner-learner interactions within a group engaged in constructing a culture of shared understanding and artifacts. Conceiving science departments as communities emphasizes participating 
in learning activities, sharing experiences, and communicating the meaning and value of these experiences.

Thus, applying a sociocultural conceptual framework allows us to estimate learning by analyzing students' experiences in relation to science (Leach \& Scott, 2003). A key aspect of understanding learning through this lens is that members of a science learning community acquire the skills to perform practices by interacting with educational tools, peers, and more knowledgeable members of the community (instructors) (Lave \& Wenger, 1991). As such, this conceptual framework highlights the importance of identifying the types of engagement and interactions that provide a context for learning to take place for an entire science community.

\subsection{Interactions Within a Learning Community}

The present study is grounded on a sociocultural perspective which assumes that students' learning is social and, therefore, highly affected by their interactions with others (Vygotsky, 1986). In formal educational contexts, students' interactions are determined by sociocultural practices that account for ways of talking, reading, writing, knowing, and doing (Gee, 2008). The community of learning framework also includes various types of behavior such as interactions between members of a community and how these interactions can explain the degree of human members' engagement in community goals (Lave \& Wenger, 1991). Jan \& Vlachopoulos (2018) found that the type of interaction between the participants of a learning community is a key influential factor in the formation of the community.

Some of the original views about interaction in education focused mainly on human-human interaction. Wagner (1994) characterized interaction as "reciprocal events that require at least two objects and two actions. Interactions occur when these objects and events mutually influence one another" (Wagner, 1994, p. 8). Other definitions of interaction (Beard \& Harper, 2002) refer to the social purpose and processes of interaction, particularly regarding student-student and student-instructor interactions.

Moore (1989) distinguished among three forms of interaction: (a) student-student interaction among individual students or among students working in small groups; (b) student-instructor interaction that traditionally focused on classroom-based dialogue between students and the instructor; and (c) student-content interaction which refers to students interacting with the subject matter under study to construct meaning, relate it to personal knowledge, and apply it to problem solving. According to social theories of learning and distributed cognition (Salomon, 2000), student-student interaction is desirable both for cognitive purposes and motivational support. However, student-teacher interaction is valued by both students and teachers and has been found to be associated with positive perceptions of learning (Wu \& Hiltz, 2004).

Recent studies have also utilized the framework of communities of practice to examine how science learning communities engage in science learning practices. For instance, González-Howard \& McNeill (2016) found that the interactions between students (working in smaller group structures, such as pairs) and the interactions between students and tools (linguistic resource for engaging in science discourse) promoted students' engagement in scientific argumentation. Students' engagement in scientific practices, like argumentation, by using scientific models to build explanations or framing scientific issues in their social context, depends on teacher's knowledge and practices (Chen, 2020; JiménezAleixandre, 2014; Pierson et al., 2019). 


\subsection{Distance Education-Distance Learning}

Distance education is an instruction that occurs when the instructor and student are separated by distance, time, or both (Mupinga, 2005). The communication between instructors and students can be either "synchronous" when they are present at the same time during instruction or "asynchronous" when instructors and students do not have face-toface direct interaction at the same time or place (Cannon, 2002).

Online learning is a subset of distance education embracing a wide set of technology applications and learning processes including computer-based learning, web-based learning, virtual classrooms, and digital collaborations. In that way, it is used as an umbrella term that covers various forms of teaching and learning as web-based training, e-learning, distributed learning, Internet-based learning, web-based instruction, cyber learning, virtual learning, or net-based learning (Keengwe \& Kidd, 2010).

According to OECD (2005), "E-learning refers to the use of information and communications technology (ICT) to enhance and/or support learning in post-secondary education. This implies that "e-learning" refers to both wholly online provision and campusbased or other distance-based provision supplemented with ICT in some way." Blended learning (b-learning) is a teaching and learning approach that combines both online and face-to-face modalities to create a cohesive learning experience and offer learners the advantage of flexibility in shifting time and space, among other benefits (Shu \& Gu, 2018).

Distance learning with various forms, from fully online courses to blended courses, takes place outside the traditional classroom. Several factors closely associated with the characteristics of the learning community have been identified by educators as significant concerns within the distance learning environments. The role of participants within distance learning environments is central to the development of the community. Interactions among participants are necessary and may be facilitated by an effective technological infrastructure which must create an environment of social activities adequately robust to ensure that each participant has a voice (Hodge et al., 2006).

In courses taught fully online, the instructor is not physically present. On synchronous online teaching, all participants in the learning environment are present at the same time, but not necessarily the same location. Special platforms can be used that attempt to replicate the experience of a traditional classroom with live video streaming, screen sharing, and a live chat feature that enhances the communication in real time. On asynchronous online teaching, the teaching materials are posted online, and learners work through them in their own time, communicating with each other and the teacher via discussion boards or forums or even by e-mail. Palloff \& Pratt (2007) argue that "there is one element that sets online distance learning apart from the traditional classroom setting": the central role of student-student and instructor-student interactions in the learning process. Moreover, online environments, especially the asynchronous courses, demand more responsibility from learners. A responsible student uses course material when he/she has adequate self-regulation skills. Self-regulated students take control of their learning, by developing appropriate metacognitive strategies such as planning and staying organized and motivated (Kauffman, 2015). Different levels of online experience result in different levels of motivation and self-regulation to online learning; therefore, graduate students exhibit more adaptive self-regulated learning profiles than undergraduates (Artino \& Stephens, 2009). Main barriers associated with distance learning are reported (Dietrich et al., 2020) including issues of communication 
between student and institution, isolation, tutoring, laboratory work, access to books, and informatics issues, including training of staff and the need for technical support, or even difficulties of access to a sufficiently high-performance internet connection.

\subsection{Engagement}

Student engagement has been the focus of a substantial amount of research in the last few years, as an important factor for learning outcomes in higher education. Education researchers emphasize student engagement as a key element of the development of learning communities in higher education (Ashwin \& McVitty, 2015). However, there is no unanimous conceptualization regarding student engagement among the academic community (Ashwin \& McVitty, 2015; Godec et al., 2018), a fact which may be attributed to its multidimensional nature (Ashwin \& McVitty, 2015; Fredricks et al., 2004; Godec et al., 2018; Kahu, 2013).

Fredricks et al. (2004) proposed a multidimensional view of student engagement via the identification of three dimensions: behavioral, emotional, and cognitive engagement. Behavioral engagement is linked with the notion of participation; it includes attendance in academic and social activities and results to positive academic outcomes and prevention of dropping out (Fredricks et al., 2004). The most widely accepted view of engagement in the higher education literature emphasizes student behavior and teaching practice (Kahu, 2013).

Emotional engagement encloses positive and negative reactions to teachers, classmates, academics, and school which influence the willingness to do the work. Students' affective reactions in the classroom, including interest, boredom, happiness, sadness, and anxiety are included within emotional engagement (Fredricks et al., 2004).

Finally, cognitive engagement is mainly connected with the effort required to understand complex ideas and master difficult skills (Fredricks et al., 2004). Cognitive engagement is also defined in terms of being strategic or self-regulating (Pintrich \& De Groot, 1990; Zimmerman, 1990).

Kahu (2013) associated the key problems related with the research conducted in the field of student engagements with poor definitions of the term and to an admixture between issues that should be examined separately such as the state of engagement, the factors that influence student engagement, and the consequences of engagement. Aiming to overcome these problems, Kahu (2013) suggested a conceptual framework that incorporates elements from all four existing research perspectives, namely, the behavioral, the psychological, the socio-cultural, and the holistic. The behavioral perspective highlights student behavior and institutional practice. The psychological perspective conceptualizes engagement as an individual psycho-social process. The socio-cultural perspective highlights the critical role of the socio-political context, and finally, the holistic takes a broader view of engagement. The psychological perspective is evident with the inclusion of the three dimensions of engagement - emotion, cognition, and behavior - as proposed by Fredricks et al. (2004). Student engagement is embedded within the socio-cultural context and shown as influenced by the characteristics of both the student and the institution. (Kahu, 2013). The psycho-social influences are categorized as university, relationships, and student variables that constitute a learning community. Various studies have demonstrated the influence of a learning community (teachers and students practice) on student engagement (Zhao \& Kuh, 2004). Kahu's framework (2013) recognizes the impact of curriculum and assessment on student engagement as structural influences within the university. Teaching and learning differ by discipline, with a distinction often made between the 
"soft" disciplines, such as humanities, and the "hard" disciplines, such as natural sciences (Brint et al., 2008). Finally, student engagement is considered as fundamentally situational it arises from the interplay of context and individual (Kahu, 2013).

Engagement in a twenty-first century university environment is considered as a concept including participation at face-to-face experiences such as lectures, tutorials, and practicals, and logging into and interacting with online resources (Miltiadous et al., 2020). In academic settings, engagement is closely linked with the quality of effort students make to perform well and achieve desired outcomes (Sun \& Rueda, 2012). Several factors, such as the course tutors (Richardson \& Long, 2003), and the quality of technology (Webster \& Hackley, 1997) are positively interrelated with student engagement levels in distance education environments.

Taking into account the aforementioned framework, the investigation of correlations between students' engagement and their interactions within a science learning community in both face to face and online learning environments is useful in order to shed light on the transformation of the learning experience during a shift from a traditional to a distance learning environment.

\subsection{The Present Study}

Qualitative differences in the level or degree of engagement within each one of its three specific dimensions (i.e., behavioral, cognitive, and emotional) make engagement a valuable multidimensional concept whose measurement is highly desired. Therefore, engagement can vary in intensity and duration, and it seems that engagement build-up is related to sustained interest in the long term (Fredricks et al., 2004). Engagement is emerged from an interaction of the individual with the context and is responsive to variation in environments (Finn \& Rock, 1997). Consequentially, the study of engagement as multidimensional construct and its correlation with interactions between the individual and the environment help us better understand the complexity of students' educational experiences. Moreover, various factors such as gender, academic major, and semester of study were considered based on previous research recommendations (McSporran \& Young, 2001; Ruthotto et al., 2020; Swan, 2001).

Thus, in summary, the current study addresses the following interlocking questions:

RQ1. Do students' engagement and interactions in either the traditional or the online learning environment and their obstacles to online learning differ among the different genders, the various disciplines (academic majors), or semesters of study?

RQ2. Do students' engagement and their interactions in a traditional learning environment differ from those in an online learning environment in four university-based science learning communities?

RQ3. How is a change in students' engagement in four university-based science learning communities induced during a shift from traditional to online teaching related with the changes occurring in the students' interactions?

\section{Method}

\subsection{The Context}

Tertiary education in Greece is administered at Universities and leads to the award of either a Bachelor's degree at the undergraduate level and a Master's or PhD degree at (post) 
graduate level. The Bachelor's degree is awarded in a specific academic major after completion of a program of study which is typically deployed in 4 years/8 academic semesters (full-time). However, it is not unusual for a typical Greek University student to require additional time for successful coverage of all prerequisites that lead to the degree award.

Universities offer a wide range of postgraduate study programs (departmental, interdepartmental, inter-institutional), covering a variety of scientific fields. The duration of postgraduate studies which lead to a Master's degree is 3 to 4 semesters and includes specialized courses and the elaboration of a diploma thesis.

The participants in the current study were full-time undergraduate students drawn from three different academic departments of two Universities. One of the two Universities is a large-sized tertiary institution located in the country capital (National and Kapodistrian University of Athens-NKUA), and the other is a small-sized regional University located in Western insular Greece (Ionian University-IONIO). Our sample consists of undergraduate students from the following academic departments: (a) Chemistry (CHEM-NKUA), (b) Environment (Environmental Science) (ES-IONIO), and (c) Food Science and Technology (FS-IONIO) and postgraduate (Master) students from the inter-institutional postgraduate program "Chemistry Education, Information and Communication Technology and Education for Sustainable Development" (ChemEdu-NKUA). Thus, four science learning communities: CHEM-NKUA, ES-IONIO, FS-IONIO, and ChemEdu-NKUA are the subjects of investigation. The present study focuses on students' views about both their engagement and their interactions within the learning community they participate.

In March 2020, all Greek Universities suspended their traditional on-campus function in order to prevent the spread of the COVID-19 coronavirus. Within a short period of approximately 10 days, the vast majority of the Greek university departments adapted their teaching environments from traditional to online. Synchronous and asynchronous online tools were used in order to continue the educational process even on practical classes. The aim of the present study is the investigation of how this shift from traditional to online learning environment affected students' interactions as well as their engagement, through the lens of science learning communities.

\subsection{Measures}

This section summarizes the variables, which are included in the study based on the theoretical framework, and a description of the data analysis undertaken.

Initially, two engagement scales (emotional and behavioral) and six interaction scales within a learning community (student-student [peer], student-instructor, and student-tools in both traditional and online environments) were developed based on previously published instruments (e.g., Kuo et al., 2014; Sun \& Rueda, 2012). The exploratory factor analysis of our data resulted to an engagement scale variable (corresponding to emotional engagement) and four interaction scale variables within a learning community (human and student-tools interactions in both traditional and online environments). A scale regarding the obstacles to online learning environment was also developed based on previously reported barriers associated with distance learning (Dietrich et al., 2020). Finally, the independentbackground variables are demographic variables common to most analyses: (a) gender, a dichotomous variable with two values (male and female); (b) university, a dichotomous variable with two values (NKUA and IONIO); (c) semester, a categorical variable with five values (2, 4, 6, 8, and $\geq 10$ ); (d) academic level (undergraduate and master's degree); and (e) academic major, a categorical variable with three values (CHEM-NKUA, ES-IONIO, 
and FS-IONIO). A circumstantial description of the scale variables' measures, accompanied by evidence regarding scales validity and reliability, is presented below.

\subsubsection{Emotional Engagement}

Students reported their emotional engagement using eight items about a variety of emotions related to the courses ( 4 referring to traditional and 4 referring to online learning environment). Items are about positive and negative emotions such as being enjoyable, interested, bored, fatigued, and distracted. Students' responses to each emotional engagement item were assessed using a Likert-type scale ranging from "in no case" (0) to "in all cases" (4). The item statements are presented in Tables 1 and 2.

\subsubsection{Behavioral Engagement}

Students reported their behavioral engagement using six rating items about (a) their participation in the courses' lectures, (b) the use of courses' reading material, and (c) the use of courses' slide presentations (3 items referring to traditional and 3 referring to online learning environment). Students' responses to each type of behavioral engagement item were assessed using a rating scale ranging from " $0 \%$ " to " $100 \%$." The item statements are presented in Tables 1 and 2.

\subsubsection{Interactions in a Learning Community}

Students also reported the interaction with their peers via four items related with the sharing of ideas and with their communication (2 referring to the traditional and 2 referring to the online learning environment). They also reported their interactions with the science courses instructors via six items ( 3 referring to traditional and 3 referring to online learning environment). Finally, students reported their interactions with the online educational tools via four items ( 2 referring to traditional and 2 referring to online learning environment). Students' responses to each interaction item were assessed using a Likert-type scale ranging from "in no case" (0) to "in all cases" (4). The item statements are presented in Tables 1 and 2.

\subsubsection{Obstacles to Online Learning Environment}

Students reported the obstacles that they faced during their interaction with the online learning environment via eight items. Students' responses to each item were assessed using an Osgood-type scale ranging either from "easy" (1) to "difficult" (9), or "sufficient" (1) to "deficient" (9), or "beatable" (1) to "insurmountable" (9) (Appendix 1).

\subsection{Data}

A clustered sampling by time period was used to select 360 students (101 males and 259 females) divided between the two Universities (193 in NKUA and 167 in IONIO), the three departments (193 in CHEM, 77 in ES, and 90 in FS), the two academic levels (347 undergraduate students and 13 in master's degree), and the semester of study (124 in 2nd, 64 in 4th, 60 in 6th, 62 in 8th, and 37 in 10th or higher semester for undergraduate students). Students completed the anonymous online survey during a 2-week period at the end of the 


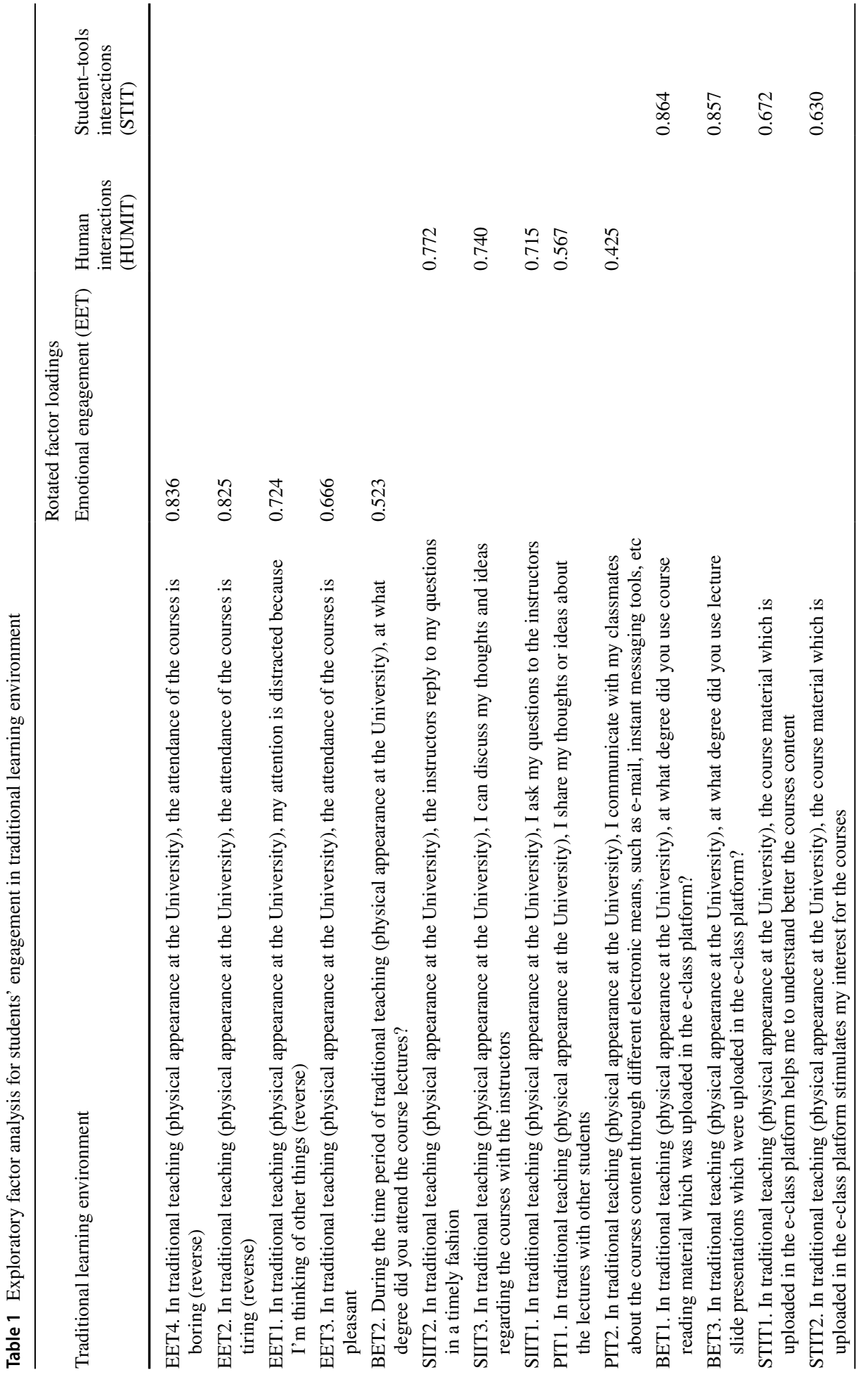




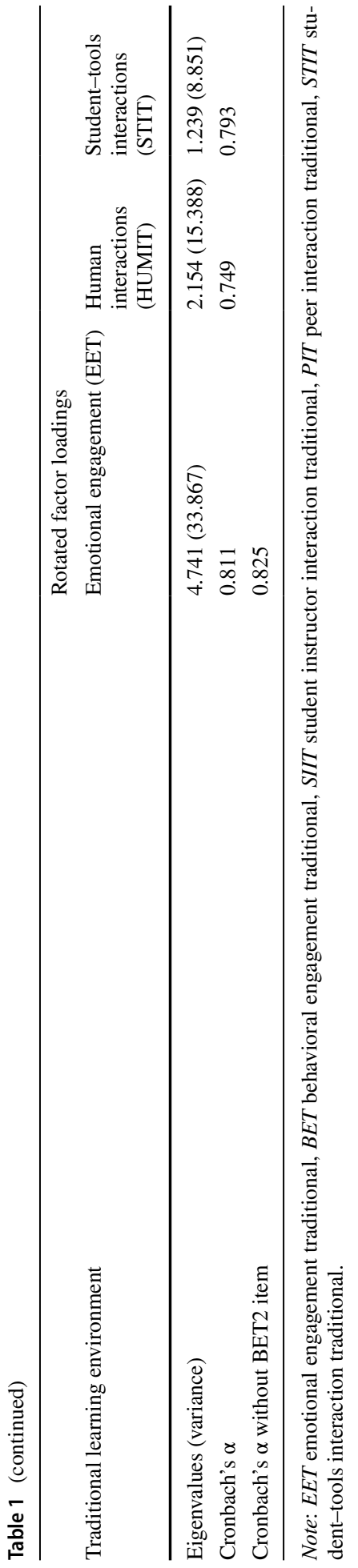




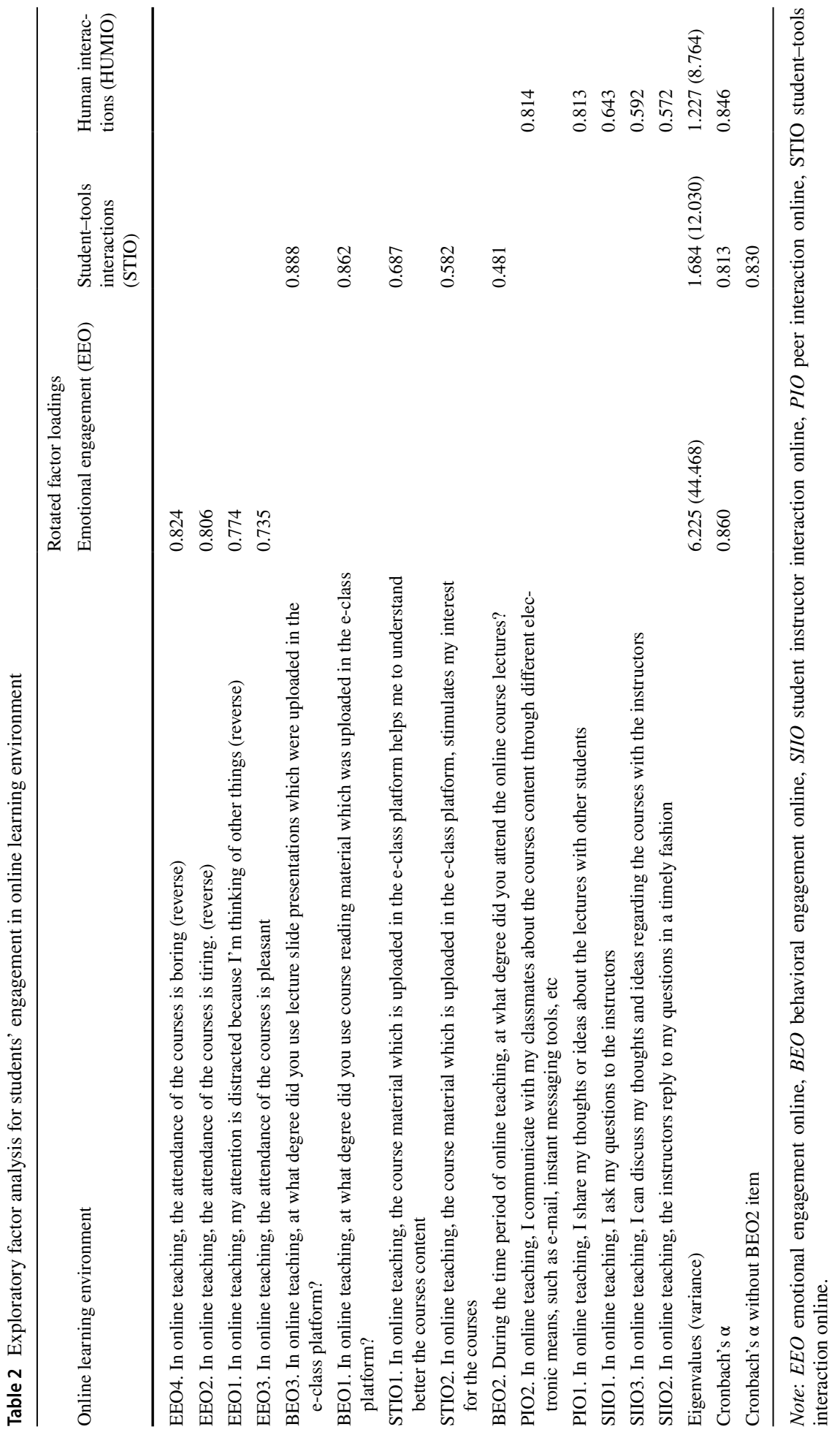


spring semester of academic year 2019-2020 (15-31 May 2020). Students were informed about the study, and they consented to participate. They participated voluntarily without extra credit or compensation for their participation. The conduction of the study was in accordance with the ethical standards of the institutional ethics committees of both Universities involved.

\subsection{Data Analysis}

\subsubsection{Validity and Reliability of Measurements}

Construct validity was estimated by a principal components exploratory factor analysis (Goodwin, 1999), which was conducted three times, namely on (a) the items regarding the traditional learning environment, (b) the equivalent items regarding the online learning environment, and (c) the items regarding the obstacles related with the online learning environment, with varimax rotation in order to examine the number of dimensions involved.

Internal consistency reliability is concerned with the homogeneity of the items within a scale. A scale is internally consistent to the extent that its items are highly intercorrelated, which accounts for the fact that the items share a common cause (DeVellis, 2016). Internal consistency was estimated via the coefficient of Cronbach's alpha $(\alpha)$ coefficient.

\subsubsection{Traditional Learning Environment}

Two tests indicate the suitability of data for a factor analysis: (a) the Kaiser-Meyer-Olkin (KMO) Measure of Sampling Adequacy, a statistic that tests whether partial correlations between variables are sufficiently small, with a value close to 1 that indicates that factor analysis should yield distinct and reliable factors; (b) Bartlett's test of sphericity, a statistic that tests whether the correlation matrix is significantly different from an identity matrix, with values of the significance level less than 0.05 that indicates that a factor analysis may be useful with the data (Field, 2013). In a factor analysis, the scree plot is a way of visualizing the magnitude of the variability associated with each one of resulted factors, so it is used in the selection of the number of factors to be considered.

The Kaiser-Meyer-Olkin measure $(\mathrm{KMO}=0.816)$ and all $\mathrm{KMO}$ values for individual items (greater than 0.634) verified the sampling adequacy for the analysis (Field, 2013; Kaiser \& Rice, 1974). Bartlett's test of sphericity gave a value of 1918.474 with a significance level $<0.001$, indicating that correlations between items are significantly different from zero (Field, 2013). Although four factors had eigenvalues larger than 1 (Kaiser's criterion; Kaiser, 1970) and in combination explained $65.316 \%$ of the variance, the scree plot did not justify this solution. Instead, the scree plot depicts a three-factor solution that explained $58.105 \%$ of the variance, as the point of slope of the line changes dramatically after the 3rd factor. As the two criteria (Kaiser and scree plot) give different results, an examination of the communalities guided our decision to use the scree plot, and then the analysis was redone specifying the extraction of three factors.

Table 1 shows the factor loadings with values higher than 0.400 after rotation. The items that cluster on the same factor suggest that factor 1 represents emotional engagement (EET), factor 2 combines the peer (PIT) and the student-instructor (SIIT) interactions and represents human interactions (denoted as HUMIT) as a whole, and factor 3 represents student-tools interactions (STIT). The items BET1 and BET3, which have been designed 
to measure behavioral engagement are loading together with items STIT1 and STIT2 that have been designed to measure student-tools interactions. The last two interactions constitute forms of students' behavior related with a particular course; thus, the factor analysis result is not unexpected.

\subsubsection{Online Learning Environment}

The Kaiser-Meyer-Olkin value obtained was 0.877, and all KMO values for individual items were greater than 0.762, also indicating the appropriateness of the factor model (Field, 2013; Kaiser \& Rice, 1974). Bartlett's test gave a value of 2648.144 with $p<0.001$, indicating the suitability of the factor model for the data under consideration. Principal component analysis resulted in three factors with eigenvalue larger than 1 (Kaiser's criterion; Kaiser, 1970) which in combination explained $65.261 \%$ of the variance. An examination of the scree plot confirmed the solution of three factors. The factor loadings with values higher than 0.400 after rotation are presented in Table 2.

The items that cluster on the same factor suggest that factor 1 represents emotional engagement in courses (EEO), factor 2 represents student-tools interactions (STIO), and factor 3 combines the peer (PIO) and the student-instructor (STIO) interactions and represents human interactions (denoted as HUMIO) as a whole. The items BEO1 and BEO3, which have been designed to measure behavioral engagement, are loading together with items STIO1 and STIO2 that have been designed to measure student-tools interactions, as also observed in the case of the traditional learning environment. The last two interactions constitute forms of students' behavior related with a particular course; thus, the factor analysis result is again not unexpected.

The exploratory factor analysis showed that the item regarding "the degree at which the students attended the course lectures (either in traditional-BET2 or in online teachingBEO2)" is incorporated in two different factors. More specifically, the one regarding traditional teaching loaded more on the factor related with "emotional engagement," while the one regarding online teaching loaded more on the one related with "student-tools interactions". In addition, it was noted that if either of these items is not considered, the corresponding scale reliability is increased (Tables 1 and 2). It was thus decided to disregard both items from the factors in the subsequent analysis.

\subsubsection{Obstacles to Online Learning Environment}

The Kaiser-Meyer-Olkin value obtained was 0.875, and all KMO values for individual items were greater than 0.837 , also indicating the appropriateness of the factor model (Field, 2013; Kaiser \& Rice, 1974). Bartlett's test gave a value of 1111.649 with $p<0.001$, indicating the suitability of the factor model for the data under consideration. Principal component analysis resulted in one factor with eigenvalue larger than 1 (Kaiser's criterion; Kaiser, 1970), which in combination explained $50.793 \%$ of the variance. An examination of the scree plot confirmed the solution of one factor. The items cluster on one unique factor with loadings ranging between 0.567 and 0.805 . This single factor represents the obstacles faced by the students during their interaction with the online learning environment (OOE). The reliability analysis resulted to a Cronbach's $\alpha$ value equal to 0.858 .

The variables related to emotional engagement, human interactions (including peer as well as student-instructor interactions), and student-tools interactions in both traditional 
and online learning environment, as well as the obstacles to online learning environment, all had high reliabilities (all Cronbach's $\alpha>0.75$ ), indicating a respectable overall reliability according to DeVellis (2016).

\section{Results}

\subsection{RQ1}

Do students' engagement and interactions in either the traditional or the online learning environment and their obstacles to online learning differ among the different genders, the various disciplines (academic majors), or semesters of study?

The three distinct academic major undergraduate programs, namely, (a) CHEM-NKUA, (b) ES-IONIO, and (c) FS-IONIO, and (d) the postgraduate program ChemEdu-NKUA, constitute the four science learning communities. In order to examine gender differences, independent sample $t$-tests were conducted for the CHEM-NKUA, ES-IONIO, and FSIONIO communities of learning. These tests demonstrate that there are no significant differences regarding the seven variables between men and women except for two cases. First, in the community ES-IONIO and during involvement in the traditional learning environment, women depicted significantly more positive emotional engagement relative to men (Men: Mean $=0.551, \mathrm{SD}=0.274$; Women: Mean $=0.708, \mathrm{SD}=0.241 ; t=-2.591, \mathrm{df}=75$, $p<0.05)$. Second, in the community CHEM-NKUA and during involvement in the online learning environment, women experienced a significantly higher human interactions factor relative to men (Men: Mean $=0.463, \mathrm{SD}=0.255$; Women: Mean $=0.578, \mathrm{SD}=0.230$; $t=-2.998, \mathrm{df}=178, p<0.05)$. Independent sample $t$-tests were not conducted for the ChemEdu-NKUA community of learning because the men's group was constituted by only one (1) member.

In Table 3, the mean values and standard deviations of the seven variables which probe students' engagement and interactions in either of the two learning environments (traditional, online) in the four distinct science learning communities (corresponding to three undergraduate academic majors and one community at the Master level) are presented together with the results of one-way analysis of variance (ANOVA) in the last two columns. The results of the multiple comparisons between learning communities extracted via the application of the Bonferroni criterion, which are related with statistically significant differences, are shown in Table 4.

A combined examination of Tables 3 and 4 leads to the following outcomes:

The science learning communities of Ionian University (ES-IONIO and FS-IONIO) display statistically significant higher mean values relative to the undergraduate learning community of Athens University (CHEM-NKUA) in the following three variables: emotional engagement in traditional teaching (EET), human interactions factor during traditional teaching (HUMIT), and the obstacles faced in the online learning environment (OOE).

Both the undergraduate and postgraduate science learning community of Athens University (CHEM-NKUA, ChemEdu-NKUA) display statistically significant higher mean value regarding the variable "student-tools interactions in online teaching" (STIO) relative to both learning communities of Ionian University (ES-IONIO and FS-IONIO). 
Table 3 Descriptive statistics and ANOVA results regarding the seven variables which characterize the four science learning communities involved in the present study

\begin{tabular}{lllllllllllll}
\hline & $\begin{array}{l}\text { CHEM-NKUA } \\
(N=180)\end{array}$ & \multicolumn{2}{l}{$\begin{array}{l}\text { ES-IONIO } \\
(N=77)\end{array}$} & \multicolumn{3}{l}{$\begin{array}{l}\text { FS-IONIO } \\
(N=90)\end{array}$} & \multicolumn{3}{l}{$\begin{array}{l}\text { ChemEdu-NKUA } \\
(N=13)\end{array}$} \\
\hline & Mean & SD & Mean & SD & Mean & SD & Mean & SD & F & Sig \\
EET & 0.5709 & 0.1867 & 0.6526 & 0.2623 & 0.7148 & 0.2106 & 0.5673 & 0.2231 & 10.028 & 0.000 \\
EEO & 0.4663 & 0.2631 & 0.4364 & 0.2794 & 0.3333 & 0.2441 & 0.4712 & 0.2051 & 5.410 & 0.001 \\
STIT & 0.6313 & 0.2180 & 0.6448 & 0.2220 & 0.6783 & 0.2076 & 0.7415 & 0.2719 & 1.718 & 0.163 \\
STIO & 0.7243 & 0.2072 & 0.6168 & 0.2482 & 0.5880 & 0.2514 & 0.8269 & 0.1420 & 10.902 & 0.000 \\
HUMIT & 0.6708 & 0.1959 & 0.7513 & 0.2046 & 0.8165 & 0.1621 & 0.8000 & 0.1369 & 13.193 & 0.000 \\
HUMIO & 0.5421 & 0.2433 & 0.5526 & 0.2673 & 0.4228 & 0.2755 & 0.5885 & 0.2493 & 5.428 & 0.001 \\
OOE & 3.4438 & 1.6522 & 4.1802 & 2.0113 & 4.1681 & 1.7927 & 3.1346 & 1.7444 & 5.476 & 0.001 \\
\hline
\end{tabular}

One science learning community of Ionian University (FS-IONIO) displays statistically significant lower mean values with one or both of the other two undergraduate learning communities (CHEM-NKUA, ES-IONIO) for two variables related with online teaching, namely the emotional engagement (EEO) and the human interactions factor (HUMIO).

In Table 5, the mean values of the seven measured variables are presented as a function of semester of study (i.e., irrespective of science learning community). More specifically, the results reported are those corresponding solely to the two semesters (among the five different possibilities) which displayed the minimum and maximum mean value for the corresponding variable.

A trend towards higher mean values regarding emotional engagement and human interactions in the traditional learning environment is observed for students in the 4th semester of study. In the online learning environment, a trend towards higher mean values regarding emotional engagement, human interactions, and student-tools interactions is observed for

Table 4 Multiple comparisons with the Bonferroni criterion

\begin{tabular}{llllll}
\hline Dependent variable & (I) Major & (J) Major & Mean difference (I-J) & Std. Error & Sig \\
\hline EET & CHEM-NKUA & ES-IONIO & $-0.08165^{*}$ & 0.02888 & 0.030 \\
& & FS-IONIO & $-0.14387^{*}$ & 0.02738 & 0.000 \\
EEO & CHEM-NKUA & FS-IONIO & $0.13299^{*}$ & 0.03361 & 0.001 \\
STIO & CHEM-NKUA & ES-IONIO & $0.10758^{*}$ & 0.03082 & 0.003 \\
& & FS-IONIO & $0.13638^{*}$ & 0.02922 & 0.000 \\
& ChemEdu-NKUA & ES-IONIO & $0.21016^{*}$ & 0.06786 & 0.013 \\
& & FS-IONIO & $0.23896^{*}$ & 0.06715 & 0.003 \\
HUMIT & CHEM-NKUA & ES-IONIO & $-0.08047^{*}$ & 0.02563 & 0.011 \\
& & FS-IONIO & $-0.14569^{*}$ & 0.02430 & 0.000 \\
HUMIO & CHEM-NKUA & FS-IONIO & $0.11931^{*}$ & 0.03319 & 0.002 \\
& ES-IONIO & FS-IONIO & $0.12982^{*}$ & 0.03990 & 0.007 \\
OOE & CHEM-NKUA & ES-IONIO & $-0.73644^{*}$ & 0.24138 & 0.015 \\
& & FS-IONIO & $-0.72431^{*}$ & 0.22885 & 0.010 \\
\hline
\end{tabular}


Table 5 The minimum and maximum mean values of the seven variables per semester of study

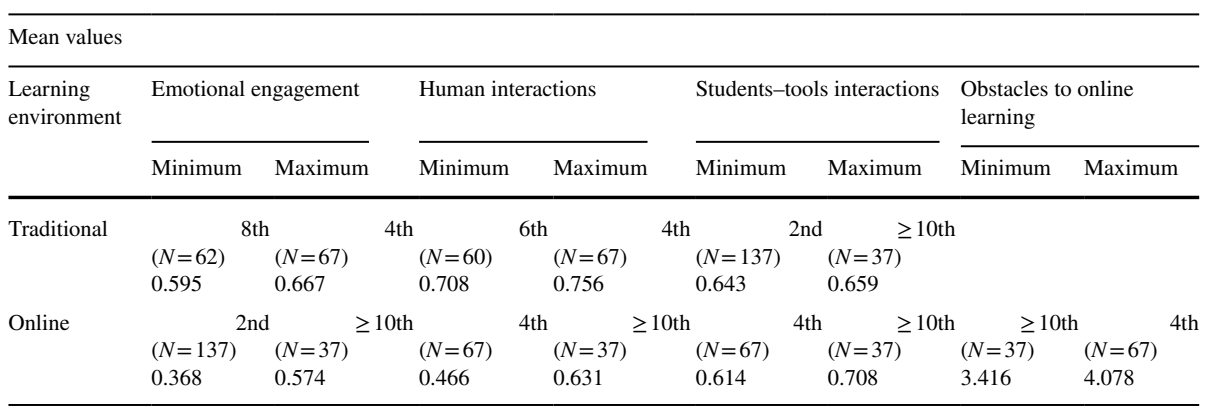

the older students being in the 10th (or higher) semester of study. The minimum number of obstacles to online learning is reported by the older students ( $\geq 10$ th semester) and the maximum by those in the 4th semester of study.

The results of one-way ANOVA together with the multiple comparisons between semesters extracted via the application of the Bonferroni criterion are shown in Table 6 . A combined examination of Tables 5 and 6 reveals that the older students $(\geq 10$ th semester of study) display statistically significant higher mean values relative to 1 st and 2 nd year students (2nd and 4th semester respectively) in the variables related with emotional engagement and human interactions in the online learning environment (EEO and HUMIO respectively).

\subsection{RQ2}

Do students' engagement and their interactions in a traditional learning environment differ from those in an online learning environment in four university-based science learning communities?

Our sample overall produced different mean values of the seven scales of the present study. Paired samples $t$-tests were conducted in order to examine for statistically significant differences regarding students' emotional engagement and their interactions, either human or with tools, as a function of the learning environment (traditional vs. online). These tests were conducted separately for the students of each learning community, and the results are shown in Table 7.

Results indicate several significant differences for all learning communities which can be summarized as follows:

Table 6 ANOVA results and multiple comparisons with the Bonferroni criterion (semester)

\begin{tabular}{llllllll}
\hline $\begin{array}{l}\text { Dependent vari- } \\
\text { able }\end{array}$ & (I) Semester & (J) Semester & $\begin{array}{l}\text { Mean difference } \\
(\mathrm{I}-\mathrm{J})\end{array}$ & Std. Error & Sig & F & Sig \\
\hline EEO scale & $\geq 10$ th semester & 2nd semester & $0.20606^{*}$ & 0.04767 & 0.000 & 6.539 & $<0.001$ \\
& & 4th semester & $0.19778^{*}$ & 0.05313 & 0.002 & & \\
HUMIO scale & $\geq 10$ th semester & 2nd semester & $0.16101^{*}$ & 0.04754 & 0.008 & 4.642 & $<0.050$ \\
& & & 4th semester & $0.16546^{*}$ & 0.05300 & 0.019 & \\
\hline
\end{tabular}


Students of all three undergraduate learning communities (CHEM-NKUA, ES-IONIO, and FS-IONIO) exhibit higher emotional engagement and human interactions in the traditional relative to the online learning environment. The same pattern applies to the students of the postgraduate learning community (ChemEdu-NKUA) with regard to the human interactions.

There is not a common pattern among the different science learning communities with regard to the student-tools interactions. Thus, students of CHEM-NKUA exhibit a lower mean value in the traditional relative to the online learning environment, while for those of FS-IONIO, an opposite trend is observed.

\subsection{RQ3}

How is a change in students' engagement in four university-based science learning communities induced during a shift from traditional to online teaching related with the changes occurring in the students' interactions?

The shift from the traditional to the online learning environment resulted to a decrease of students' emotional engagement in their courses. These changes were statistically significant for all three undergraduate science learning communities (CHEM-NKUA, ESIONIO, and FS-IONIO). Although the variable related to the human interactions between the members of the communities depicts the same pattern, this does not seem to apply to the student-tools interactions as well, as noted above. Therefore, we were interested in examining whether the change in students' emotional engagement can be predicted from the changes in either human and student-tools interactions in a science community or the obstacles in the online learning environment.

For this purpose, based on our data for the two learning environments (traditional and online), the following new variables were computed: (a) the emotional engagement change $\Delta \mathrm{EE}(\Delta \mathrm{EE}=\mathrm{EEO}-\mathrm{EET})$; (b) the human interactions' change within a learning community $\Delta$ HUMI $(\Delta$ HUMI $=$ HUMIO - HUMIT $)$; and (c) the student-tools interactions change within a learning community $\Delta \mathrm{STI}(\Delta \mathrm{STI}=\mathrm{STIO}-\mathrm{STIT})$. Then a multiple regression analysis was conducted for each science learning community. The outcome variable $Y$ is the emotional engagement change $(\Delta \mathrm{EE})$, and the predictor variables are $\mathrm{X}_{1}$ : the change in human interactions within a learning community $(\Delta \mathrm{HUMI}) ; \mathrm{X}_{2}$ : the change in student-tools interactions within a learning community $(\Delta \mathrm{STI})$; and $\mathrm{X}_{3}$ : the obstacles in the online learning environment (OOE).

Table 8 presents the correlation coefficients of each variable with the others. The correlation matrix gives us a rough idea of the relationships between the outcome and predictor variables, and a preliminary check for multicollinearity. In our case, there are no substantial correlations $(r>0.90)$ between the predictors, which provides evidence that there is no multicollinearity in the data (Field, 2013). As seen in Table 8, of all predictors, the change of human interactions ( $\triangle \mathrm{HUMI}$ ) between the members of a science learning community shows the highest correlations $(0.616 \leq r \leq 0.796)$ with the outcome variable, and it is thus likely that this variable is the best predictor of the observed change in students' emotional engagement $(\Delta \mathrm{EE})$.

Table 9 contains information about the fit of different regression models in predicting students' emotional engagement. Model 1 uses only the change in human interactions ( $\triangle$ HUMI) between the members of a science learning community as a predictor. Model 2 uses two variables, namely the change in human ( $\Delta$ HUMI) as well as in student-tools interactions $(\Delta \mathrm{STI})$ between the members of a science learning community as predictors. 


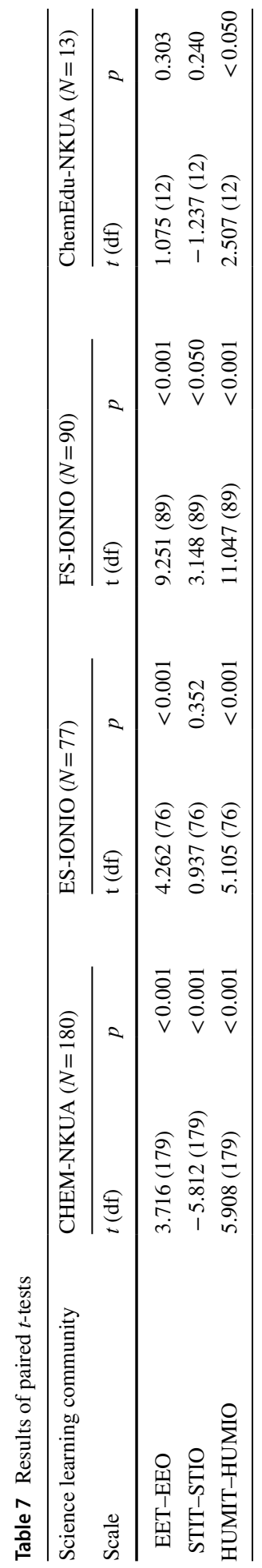


Table 8 Pearson $r$ coefficients for our variables

\begin{tabular}{|c|c|c|c|c|c|}
\hline Science learning community & & $\Delta \mathrm{EE}$ & $\Delta$ HUMI & $\Delta \mathrm{STI}$ & OOE \\
\hline \multirow[t]{8}{*}{ CHEM-NKUA $(N=180)$} & $\Delta \mathrm{EE}$ & & $0.616^{* *}$ & $0.333 * *$ & $-0.410^{* *}$ \\
\hline & $\Delta$ HUMI & $0.616 * *$ & & $0.360 * *$ & $-0.445^{* *}$ \\
\hline & $\Delta \mathrm{STI}$ & $0.333 * *$ & $0.360 * *$ & & $-0.172 *$ \\
\hline & OOE & $-0.410 * *$ & $-0.445^{* *}$ & $-0.172 *$ & \\
\hline & $\Delta \mathrm{EE}$ & & $0.727 * *$ & $0.485^{* *}$ & -0.564 \\
\hline & $\Delta$ HUMI & $0.727 * *$ & & $0.697 * *$ & -0.580 \\
\hline & $\Delta \mathrm{STI}$ & $0.485 * *$ & $0.697 * *$ & & -0.487 \\
\hline & OOE & $-0.564 * *$ & $-0.580 * *$ & $-0.487 * *$ & \\
\hline \multirow[t]{4}{*}{ FS-IONIO $(N=90)$} & $\Delta \mathrm{EE}$ & & $0.796 * *$ & $0.486 * *$ & $-0.557 * *$ \\
\hline & $\Delta$ HUMI & $0.796 * *$ & & $0.531 * *$ & $-0.566^{* *}$ \\
\hline & $\Delta \mathrm{STI}$ & $0.486 * *$ & $0.531 * *$ & & $-0.464 * *$ \\
\hline & OOE & $-0.557 * *$ & $-0.566 * *$ & $-0.464 * *$ & \\
\hline \multirow[t]{4}{*}{ ChemEdu-NKUA $(N=13)$} & $\Delta \mathrm{EE}$ & & $0.710^{*}$ & -0.358 & $-0.633 *$ \\
\hline & $\Delta$ HUMI & $0.710 *$ & & 0.136 & $-0.647 *$ \\
\hline & $\Delta \mathrm{STI}$ & -0.358 & 0.136 & & 0.216 \\
\hline & OOE & $-0.633^{*}$ & $-0.647 *$ & 0.216 & \\
\hline
\end{tabular}

**Correlation is significant at the 0.01 level (1-tailed)

*Correlation is significant at the 0.05 level (1-tailed)

Finally, model 3 uses all three variables as predictors. Each set of summary statistics is repeated for each science learning community (Appendix Table 10).

In the CHEM-NKUA community, the $R^{2}$ value for the first model is 0.380 , which means that the change in human interactions ( $\triangle \mathrm{HUMI}$ ) accounts for $38.0 \%$ of the variation in the students' change of emotional engagement $(\Delta \mathrm{EE})$. Moreover, when the other two predictors are sequentially included (model 2 and model 3) this value increases to $39.4 \%$ and $41.7 \%$ respectively. The inclusion of the two additional predictors explains a larger portion of the variation relative to model 1 , but by an amount which is not large enough to support the necessity for either model 2 or 3 . An ANOVA is used to test which of the models is significantly better at predicting the outcome variable. For model 1 , the $F$-ratio is 108.991 , which is very unlikely to have happened by chance $(p<0.001)$. For the second and third models, the values of $F$ are lower (57.514 and 41.880, respectively), which are also highly significant $(p<0.001)$. These results mean that model 1 significantly predicts the outcome variable, but the models with the additional predictors are not better because of the lower values of the $F$-ratio.

The results regarding the ES-IONIO as well as the FS-IONIO community are very similar. In fact, it is shown that model 1 leads to quite large $R^{2}$ value which is equal to 0.528 and 0.634 for ES-IONIO and FS-IONIO, respectively. Following the examination of the different statistical indices, the necessity for the inclusion of additional predictors (models 2 and 3 ) is similarly not justified for either of these two learning communities as well.

Finally, for the learning community regarding the ChemEdu-NKUA postgraduate program, the $R^{2}$ value for the first model is 0.504 . However, when the other two predictors are included (model 2 and model 3), this value increases to $71.4 \%$ and $71.6 \%$, respectively. Therefore, if the change in human interactions ( $\Delta \mathrm{HUMI})$ accounts for $50.4 \%$ of 
Table 9 Regression model summary and ANOVA

\begin{tabular}{lllllrllll}
\hline & Model & $R$ & $R$ square & $\begin{array}{l}\text { Adjusted } R \\
\text { square }\end{array}$ & \multicolumn{1}{l}{$F$} & df & Sig & Durbin-Watson \\
\hline CHEM-NKUA & 1 & 0.616 & 0.380 & 0.376 & 108.991 & $(1,178)$ & 0.000 & \\
& 2 & 0.628 & 0.394 & 0.387 & 57.514 & $(2,177)$ & 0.000 & \\
& 3 & 0.645 & 0.417 & 0.407 & 41.880 & $(3,176)$ & 0.000 & 2.030 \\
ES-IONIO & 1 & 0.727 & 0.528 & 0.522 & 83.881 & $(1,75)$ & 0.000 & \\
& 2 & 0.727 & 0.529 & 0.516 & 41.522 & $(2,74)$ & 0.000 & \\
& 3 & 0.750 & 0.562 & 0.544 & 31.202 & $(3,73)$ & 0.000 & 2.003 \\
FS-IONIO & 1 & 0.796 & 0.634 & 0.630 & 152.518 & $(1,88)$ & 0.000 & \\
& 2 & 0.800 & 0.640 & 0.631 & 77.220 & $(2,87)$ & 0.000 & \\
& 3 & 0.808 & 0.653 & 0.641 & 53.890 & $(3,86)$ & 0.000 & 1.943 \\
ChemEdu- & 1 & 0.710 & 0.504 & 0.459 & 11.180 & $(1,11)$ & 0.007 & \\
NKUA & 2 & 0.845 & 0.714 & 0.657 & 12.493 & $(2,10)$ & 0.002 & \\
& 3 & 0.846 & 0.716 & 0.622 & 7.575 & $(3,9)$ & 0.008 & 2.195 \\
\hline
\end{tabular}

Dependent Variable: $\Delta$ EEModel 1. Predictors: (Constant), $\Delta$ HUMIModel 2. Predictors: (Constant), $\Delta$ HUMI, $\Delta$ STIModel 3. Predictors: (Constant), $\Delta$ HUMI, $\Delta$ STI, OOE

the variation, the change in student - tools interactions $(\Delta \mathrm{STI})$ accounts for an additional $21.0 \%$. Thus, the inclusion of the new predictor (model 2) has explained a quite larger amount of the variation in the outcome variable. Finally, the inclusion of the third variable (model 3) does not significantly increase further the value of $R^{2}$. An ANOVA is used to test which of the models is significantly better at predicting the outcome variable. For model 1 , the $F$-ratio is 11.180 , which is very unlikely to have happened by chance $(p=0.007)$. For the second and third models, the values of $F$ are 12.493 and 7.575, which are also highly significant $(p=0.002$ and $p=0.008)$. These results mean that model 1 significantly predicts the outcome variable; however, model 2 which includes an additional extra predictor $(\Delta \mathrm{STI})$ is better because the $F$-ratio is more significant.

For all models in each science learning community, the Durbin-Watson values are found so close to 2 that the assumption of independent errors has almost certainly been met (Field, 2013).

In multiple regression, the model is described via an equation of the following form:

$$
Y=\beta_{0}+\beta_{1} X_{1}+\beta_{2} X_{2}+\ldots
$$

The regression model coefficients and collinearity statistics are presented in Appendix Table 10. Estimates for $\beta$ values indicate the individual contribution of each predictor to the model, that is, the degree at which each predictor affects the outcome variable, if the effect of all other predictors is held constant. Moreover, the VIF values are all well below 10 , and the tolerance statistics are well above 0.2 ; therefore, no collinearity within our data can be concluded (Field, 2013).

Based on the above-described analysis, the $t$-tests statistics, and the unstandardized coefficients $\beta$ (Appendix Table 10), the following four model equations (one for each science learning community) were extracted.

$$
\text { CHEM - NKUA : } \quad \Delta \mathrm{EE}=-0.002+0.796 \Delta \mathrm{HUMI}
$$




$$
\begin{aligned}
& \text { ES }- \text { IONIO : } \Delta \mathrm{EE}=-0.028+0.947 \Delta \mathrm{HUMI} \\
& \text { FS }- \text { IONIO : } \Delta \mathrm{EE}=-0.019+0.921 \Delta \mathrm{HUMI}
\end{aligned}
$$

$$
\text { ChemEdu }- \text { NKUA }: \Delta \mathrm{EE}=0.128+0.819 \Delta \mathrm{HUMI}-0.599 \Delta \mathrm{STI}
$$

\section{Discussion}

The COVID-19 pandemic has changed our norms and habits, particularly in university science departments. The adaptation of distance, online learning with a level of quality constitutes a big challenge for science educators. The present study investigated students' views regarding their engagement and their interactions within the science learning community in which they participate under two circumstances: (a) a traditional learning environment with physical presence on-campus and (b) an online learning environment adopted during the COVID-19 pandemic in Spring 2020.

The first research question examined the possible influence of the seven measured variables (emotional engagement [traditional-online], human interactions [traditionalonline], student-tools interactions [traditional-online], and obstacles to online learning) by different characteristics of the science learning community and more specifically the following: gender, university, academic major, and semester of study. The results of data analysis reveal very few gender differences regarding students' engagement and their interactions within the four different learning communities and in both learning environments. This small gender effect is consistent with findings of research related to motivation to learn science subjects (Salta \& Koulougliotis, 2020). The variable related to student-tools interactions in the traditional learning environment (STIT) was shown to be similar in all four science learning communities, and therefore, no evidence is provided for it being influenced by some specific characteristic of the science learning community.

Four variables, namely two referring to the traditional learning environment (emotional engagement [EET] and human interactions [HUMIT]) and two referring to the online learning environment (student-tools interactions [STIO] and obstacles to online learning [OOE]), display statistically significant differences between the two universities, while they are similar for the two academic majors of the same university (ES-IONIO and FS-IONIO). Therefore, it seems that the university is a significant characteristic that influences these four variables. When exposed to the traditional learning environment, the students of Ionian University display a higher level of emotional engagement (variable EET) as well as human interactions factor (variable HUMIT) relative to those of Athens University. This finding could be due to the unique distinct characteristics of the two institutions related with their size and geographic location. The much smaller size of Ionian University relative to the one of Athens University (which is the largest in the country) and its location in different small islands of the Ionian Sea which are quite far from the densely populated Greek capital (Athens) is possible to promote students' connections with their peers and instructors as well as the academic work. When exposed to the online learning environment, the students of Ionian University report more obstacles to online learning (variable OOE) relative to those of Athens University, a fact that could explain (or 
be related in some other way) with the finding that they also report a lower level of student-tools interaction factor (variable STIO). The differences between the two universities regarding the latter two variables (OOE and STIO) could also be attributed to distinct institutional characteristics like the ones discussed above as well as others, related for example with infrastructure.

The remaining two variables, both referring to the online learning environment, namely emotional engagement (EEO) and human interactions (HUMIO), display statistically significant differences between the two majors of the same university (ES-IONIO and FS-IONIO), while they are similar for two academic majors of different universities (CHEM-NKUA and ES-IONIO). Therefore, it seems that the academic major is a significant characteristic that influences these two variables. When exposed to the online learning environment, the students following the academic major "Food Science and Technology" (FS-IONIO) report a lower level of both emotional engagement and human interactions relative to those following the other two academic majors (either Environmental Science at Ionian University or Chemistry at Athens University). This finding could be related with various factors such as the classes' size differences (Ruthotto et al 2020) and the extent of use of interactive technologies (Park \& Kim, 2020) in each learning community. The much more applied nature of Food Science and Technology relative to the other two majors and/or the possible negative attitudes of the academic personnel of the specific science department towards the online learning approach could also be related with the observed low level of emotional engagement (EEO) and human interactions (HUMIO) in the online learning environment.

Finally, the semester of study is another characteristic that was shown to influence some of the measured variables. More specifically, the data analysis revealed that, when exposed to the online learning environment, the students who have already spent at least 4 years in their undergraduate studies (irrespective of university or academic major) report higher level of emotional engagement (variable EEO) and human interactions factor (HUMIO) relative to those who are found in the first (freshman) or second (sophomore) year of their studies. Analogous trend was reported by Ruthotto et al. (2020), who found that adults are more likely to actively participate (interact with peers, instructor, content, and context) in online environment than are younger graduate students. Older students seem to be more motivated, better at communication online and at scheduling their learning (Artino \& Stephens, 2009; McSporran $\&$ Young, 2001). A possible explanation is that students with more experience are more familiar with the online settings (Wang et al., 2013). The more experienced students feel more confident about their ability to communicate and learn online, tend to have a clear understanding of what is required to succeed in the course and also be more conscientious of how well they are performing in the course (Kauffman, 2015; Palmer \& Holt, 2009). Moreover, the higher emotional engagement in online learning environment of older students could be related either with work and family commitments or their need to complete their undergraduate studies and move on to their professional aspirations. Therefore, they are more flexible (relative to the freshmen and sophomores) in adopting an alternative learning environment in order to achieve their more urgent academic goals.

The second and third research questions aim to investigate the possible changes in students' emotional engagement and interactions induced upon the abrupt transition from the traditional to the online learning environment imposed by the COVID19 outbreak. With regard to emotional engagement, students of all three undergraduate 
learning communities (CHEM-NKUA, ES-IONIO, and FS-IONIO) report higher mean values in the traditional relative to the online learning environment, while no statistically significant change is reported for the postgraduate learning community (ChemEdu-NKUA). The higher mean level of the traditional relative to the online learning environment applies also to the human interactions factor, with statistically significant differences observed in all four examined learning communities. Although research has shown that students feel greater connection with instructors and their peers in online courses when instructors use interactive technologies consistently and purposefully (Park \& Kim, 2020), it seems that the abrupt shift from the traditional face-to-face in-campus education to an online learning environment due to COVID-19 pandemic did not allow the use of technology to its fullest potential.

On the other hand, no unanimous trend was observed with regard to the student-tools interaction factor; for this variable, the traditional learning environment exhibits higher mean value relative to the online solely for the FS-IONIO community, with an opposite trend being evidenced for the CHEM-NKUA community and no statistically significant difference for the remaining two communities (ESIONIO and ChemEdu-NKUA). From the above results, it may be deduced that the documented statistically significant changes in undergraduate students' emotional engagement are closely connected and possibly explained mostly via the changes in the human interactions factor and not with those related with the interactions of the students with the tools. This assumption was in fact confirmed for all three undergraduate science learning communities via the multiple regression analysis presented in Section 4.

Only in the case of the postgraduate learning community (ChemEdu-NKUA), it was shown that both the changes in the human interactions factor as well as those in the student-tools interactions are required in order to predict the change in emotional engagement experienced via the shift from the traditional to the online learning environment. The opposing influence of the two predictors ( $\Delta \mathrm{HUMI}$ and $\Delta \mathrm{STI}$ ), as evidenced by the opposite signs in the corresponding regression equation (Eq. 4), is consistent with the statistically non-significant difference in emotional engagement observed for the ChemEdu-NKUA community in the paired $t$-tests (Table 7).

The fact that the human interaction factor seems to be a strong predictor of students' emotional engagement is consistent with previous research findings which have pointed out the fact that in online education some instructors' practices tend to enhance the feeling of isolation experienced by the students (Berge \& Muilenburg, 2001). In addition, the possible catalytic role of an inertia against any change to the teaching practice should also be taken into consideration. In accordance to this notion, it has been reported that during online learning, instructors tend to simply place their lecture-based content online and not actively adopt a new instructional strategy (Palloff \& Pratt, 2007). The insistence in employing traditional teaching tools, even in an online learning environment, seems to be associated with problems of retention, low levels of learning, and low satisfaction rates (Swan, 2001).

Overall, the results of the present study provide evidence that students' interactions constitute an essential element for developing emotional engagement and consequently a sense of community. Specifically, students' emotional engagement can be best promoted by student-instructor and student-student interaction than by student-tools interaction in accordance to Jiang' argumentation (Jiang, 2017). Since the low emotional engagement in the online learning environment could result in academic failure (Finn \& Rock, 1997), online courses must be transformed to being more interactive 
and towards promoting collaboration in order to facilitate reflection as learning occurs (Kauffman, 2015).

\section{Conclusions}

According to the research questions set, the main conclusions reached in the current work may be organized as follows: With reference to the first research question, this study showed that students' gender does not seem to play a significant role with regard to their emotional engagement and interactions (either human or with tools) in either learning environment (traditional, online). The following four variables showed a tendency to be differentiated among the students of the two universities: emotional engagement and human interactions in the traditional learning environment, student-tools interactions, and obstacles in the online learning environment. Two variables, namely emotional engagement and human interactions in the online learning environment, tended to be differentiated among students of different academic majors (irrespective of university). One variable, student-tools interactions in the traditional learning environment, was not shown to be differentiated among the students of the four science learning communities. Finally, the students frequenting in more advanced semesters of study tended to be more favorable towards the online learning environment relative to younger students as evidenced by their reporting higher mean values regarding the corresponding variables of emotional engagement and human interactions. Distinct experiences in the four university-based science learning communities result to a variety of human interactions and emotional engagement. A tendency towards more favorable engagement in online learning environments with the increase of expertise becomes evident. With regard to the second research question, our study showed an overall tendency for a higher level of emotional engagement as well as human interaction in the traditional relative to the online learning environment. No overall tendency was evidenced with regard to the student-tools interaction.

Finally, taking also into account the third research question, our results point to the main conclusion reached by the current study: university students show an overall preference (in the form of stronger emotional engagement) towards the traditional relative to the online learning environment; this preference is mainly attributed to changes in the human interactions, that is, to difficulties that the members of science learning communities (both students and instructors) face in their effort to reestablish their in-between connections upon an abrupt transition in a new learning environment. This conclusion implies that upon adoption of an online (distance) learning scheme, instructors should undertake action in the direction of maintaining their communication, collaboration, and personal interaction with their students. In addition, instructors should make a conscious effort to encourage student-student interaction. Such actions are expected to keep students emotionally engaged with the learning community thus leading to a more effective and fruitful distance learning experience. 


\section{Limitations}

The main limitation of the current study is related with the fact that the conclusions reached are supported solely by quantitative data. Additional limitations are related with the small size of the subsample concerning the postgraduate community which gives rise to concern regarding its comparison with the undergraduate communities and with the fact that universities are, by nature, very complex organizations and thus difficult to characterize comparatively based solely on statistical inference. The upsurge of a worldwide life-threatening epidemic like the one of COVID-19 brings out the need for the adoption of effective online teaching approaches to ensure the continuation of the educational process. Future research should thus focus on the parallel undertake of qualitative study (e.g., student and/or instructor interviews) which would contribute to a deeper understanding of the factors determining students' engagement as well as the interactions within a learning community upon participation in either a traditional or a distance online learning environment. This would provide the possibility for a more successful and effective inclusion of various asynchronous and synchronous online tools in the teaching process which will take into account the various factors associated with the formation and dynamics of an online learning community.

\section{Appendix 1}

Obstacles to online learning environment

OOLE1. In online teaching, the access to online material uploaded in the e-class platform was easy (1)difficult (9)

OOLE2.In online teaching, the home environment influenced my participation in the online class, since it was quiet (1)-noisy (9)

OOLE3. In online teaching, the access to modern technological equipment at home was easy (1)-difficult (9)

OOLE4. My skills regarding the use of the digital media required for my participation in online classes were sufficient (1)-deficient (9)

OOLE5. The support from my peers regarding online teaching was sufficient (1)-deficient (9)

OOLE6. In online teaching, the access to domestic Internet network with satisfactory speed was easy (1)difficult (9)

OOLE7. The guidance provided by the University with regard to online teaching was sufficient (1)-deficient (9)

OOLE8. The technical problems during online teaching (e.g., network quality, connection disruption, and sound quality) were beatable (1)-insurmountable (9) 


\section{Appendix 2}

Table 10 Regression Model Coefficients and Collinearity Statistics

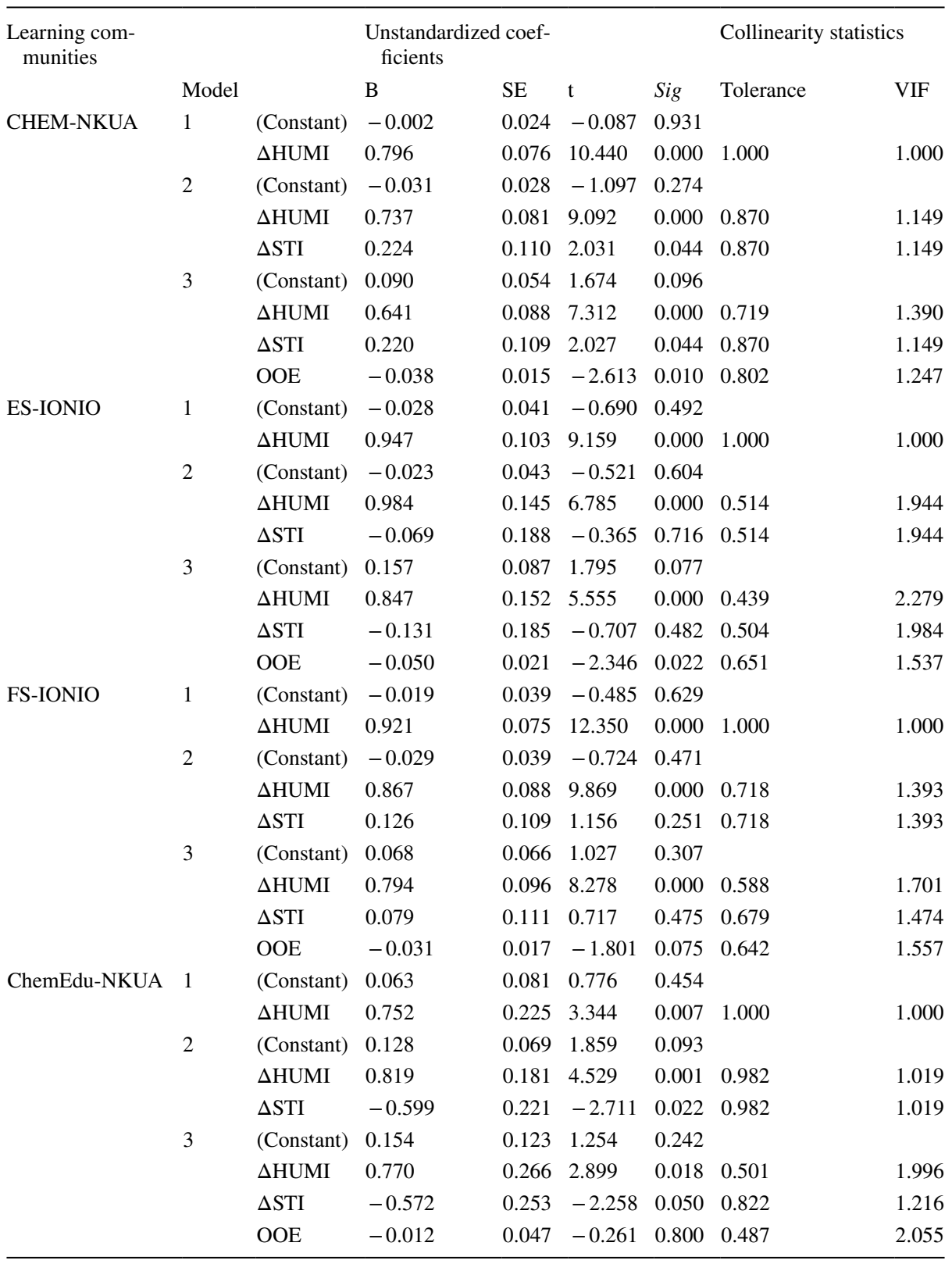


Code availability Not applicable.

\section{Declarations}

Conflict of interest The authors declare that they have no conflict of interest.

\section{References}

Al-Gahtani, S. S. (2016). Empirical investigation of e-learning acceptance and assimilation: A structural equation model. Applied Computing and Informatics, 12(1), 27-50.

Appleton, J. J., Christenson, S. L., Kim, D., \& Reschly, A. L. (2006). Measuring cognitive and psychological engagement: Validation of the student engagement instrument. Journal of School Psychology, 44(5), 427-445.

Artino, A. R., Jr., \& Stephens, J. M. (2009). Academic motivation and self-regulation: A comparative analysis of undergraduate and graduate students learning online. The Internet and Higher Education, 12(34), 146-151.

Ashwin, P., \& McVitty, D. (2015). The meanings of student engagement Implications for policies and practices. In A. Curaj, L. Matei, R. Pricopie, J. Salmi, \& P. Scott (Eds.), The European Higher Education Area. (pp. 343-359). Springer.

Bateman, H. V. (2002). Sense of community in the school. In A. T. Fisher, C. C. Sonn, \& B. J. Bishop (Eds.), Psychological sense of community: Research, applications, and implications. (pp. 161-179). Springer.

Beard, L. A., \& Harper, C. (2002). Student perceptions of online versus on campus instruction. Education, 122(4), 658-663.

Berge, Z. L., \& Muilenburg, L. (2001). Obstacles faced at various stages of capability regarding distance education in institutions of higher education. TechTrends, 45(4), 40-45.

Brint, S., Cantwell, A., \& Hanneman, R. (2008). The two cultures of undergraduate academic engagement. Research in Higher Education, 49(5), 383-402.

Cannon, J. R. (2002). Distance learning in science education. In J. W. Altschuld \& D. D. Kumar (Eds.), Evaluation of Science and Technology Education at the Dawn of a New Millennium. (pp. 243-265). Kluwer Academic/Plenum Publishers.

Chen, Y. C. (2020). Dialogic pathways to manage uncertainty for productive engagement in scientific argumentation. Science \& Education, 29(2), 331-375.

Cobb, P. (1994). Where is the mind? Constructivist and sociocultural perspectives on mathematical development. Educational Researcher, 23(7), 13-19.

DeVellis, R. F. (2016). Scale development: Theory and applications. (4th ed.). Sage.

Dewey, J. (1938). Experience and education. Macmillan Publishing Company.

Dietrich, N., Kentheswaran, K., Ahmadi, A., Teychené, J., Bessière, Y., Alfenore, S., et al. (2020). Attempts, successes, and failures of distance learning in the time of COVID-19. Journal of Chemical Education., 97(9), 2448-2457.

Field, A. (2013). Discovering statistics using SPSS. (4th ed.). Sage.

Finn, J. D., \& Rock, D. A. (1997). Academic success among students at risk for school failure. Journal of Applied Psychology, 82(2), 221-234.

Fredricks, J. A., Blumenfeld, P. C., \& Paris, A. H. (2004). School engagement: Potential of the concept, state of the evidence. Review of Educational Research, 74(1), 59-109.

Gee, J. P. (2008). A sociocultural perspective on opportunity to learn. In P. A. Moss, D. C. Pullin, J. P. Gee, E. H. Haertel, \& L. J. Young (Eds.), Assessment, equity, and opportunity to learn. (pp. 76-108). Cambridge University Press.

Godec, S., King, H., Archer, L., Dawson, E., \& Seakins, A. (2018). Examining student engagement with science through a bourdieusian notion of field. Science \& Education, 27(5-6), 501-521.

González-Howard, M., \& McNeill, K. L. (2016). Learning in a community of practice: Factors impacting English-learning students' engagement in scientific argumentation. Journal of Research in Science Teaching, 53(4), 527-553.

Goodwin, L. D. (1999). The role of factor analysis in the estimation of construct validity. Measurement in Physical Education and Exercise Science, 3(2), 85-100. 
Hodge, E., Bossé, M. J., Faulconer, J., \& Fewell, M. (2006). Mimicking proximity: The role of distance education in forming communities of learning. International Journal of Instructional Technology and Distance Learning, 3(12), 3-12.

Hong, J. C., Tai, K. H., Hwang, M. Y., Kuo, Y. C., \& Chen, J. S. (2017). Internet cognitive failure relevant to users' satisfaction with content and interface design to reflect continuance intention to use a government e-learning system. Computers in Human Behavior, 66, 353-362.

Jan, S. K., \& Vlachopoulos, P. (2018). Influence of learning design of the formation of online communities of learning. International Review of Research in Open and Distributed Learning. https://doi.org/10. 19173/irrodl.v19i4.3620.

Jiang, W. (2017). Interdependence of roles, role rotation, and sense of community in an online course. Distance Education, 38(1), 84-105.

Jiménez-Aleixandre, M. P. (2014). Determinism and underdetermination in genetics: Implications for students' engagement in argumentation and epistemic practices. Science \& Education, 23(2), 465-484.

Kahu, E. R. (2013). Framing student engagement in higher education. Studies in Higher Education, 38(5), $758-773$.

Kaiser, H. F. (1970). A second-generation little jiffy. Psychometrika, 35, 401-415.

Kaiser, H. F., \& Rice, J. (1974). Little jiffy, mark 4. Educational and Psychological Measurement, 34(1), $111-117$.

Kauffman, H. (2015). A review of predictive factors of student success in and satisfaction with online learning. Research in Learning Technology. https://doi.org/10.3402/rlt.v23.26507.

Keengwe, J., \& Kidd, T. T. (2010). Towards best practices in online learning and teaching in higher education. MERLOT Journal of Online Learning and Teaching, 6(2), 533-541.

Kelly, G. J. (2007). Discourse in science classrooms. In S. K. Abell \& N. G. Lederman (Eds.), Handbook of research on science education. (pp. 443-469). Lawrence Erlbaum.

Kuo, Y. C., Walker, A. E., Schroder, K. E., \& Belland, B. R. (2014). Interaction, Internet self-efficacy, and self-regulated learning as predictors of student satisfaction in online education courses. The Internet and Higher Education, 20, 35-50.

Lave, J., \& Wenger, E. (1991). Situated learning: Legitimate peripheral participation. Cambridge University Press.

Leach, J., \& Scott, P. (2003). Individual and sociocultural views of learning in science education. Science \& education, 12(1), 91-113.

Luo, N., Zhang, M., \& Qi, D. (2017). Effects of different interactions on students' sense of community in e-learning environment. Computers \& Education, 115, 153-160.

McSporran, M., \& Young, S. (2001). Does gender matter in online learning? ALT-J. Research in Learning Technology, 9(2), 3-15.

Miltiadous, A., Callahan, D. L., \& Schultz, M. (2020). Exploring engagement as a predictor of success in the transition to online learning in first year chemistry. Journal of Chemical Education, 97(9), 2494-2501.

Moore, M. G. (1989). Three types of interaction. American Journal of Distance Education, 3(2), 1-6.

Mupinga, D. M. (2005). Distance education in high schools: Benefits, challenges, and suggestions. The Clearing House: A Journal of Educational Strategies, Issues and Ideas, 78(3), 105-109.

OECD. (2005). E-learning in tertiary education: Where do we stand? OECD Publishing.

Oliveira, A. W., Akerson, V. L., \& Oldfield, M. (2012). Environmental argumentation as sociocultural activity. Journal of Research in Science Teaching, 49(7), 869-897.

Osterman, K. F. (2000). Students' need for belonging in the school community. Review of Educational Research, 70(3), 323-367.

Palloff, R. M., \& Pratt, K. (2007). Building online learning communities: Effective strategies for the virtual classroom. John Wiley \& Sons.

Palmer, S. R., \& Holt, D. M. (2009). Examining student satisfaction with wholly online learning. Journal of Computer Assisted Learning, 25(2), 101-113.

Park, C., \& Kim, D. G. (2020). Exploring the roles of social presence and gender difference in online learning. Decision Sciences Journal of Innovative Education, 18(2), 291-312.

Pierson, A. E., Clark, D. B., \& Kelly, G. J. (2019). Learning Progressions and science practices. Science \& Education, 28(8), 833-841.

Pintrich, P. R., \& De Groot, E. (1990). Motivated and self-regulated learning components of academic performance. Journal of Educational Psychology, 82(1), 33-40.

Richardson, J. T. E., \& Long, G. L. (2003). Academic engagement and perceptions of quality in distance education. Open Learning, 18(3), 223-244.

Rovai, A. P. (2002). Building sense of community at a distance. International Review of Research in Open and Distance Learning, 3(1), 1-16. 
Rovai, A. P., \& Barnum, K. T. (2003). On-line course effectiveness: An analysis of student interactions and perceptions of learning. Journal of Distance Learning, 18(1), 57-73.

Ruthotto, I., Kreth, Q., Stevens, J., Trively, C., \& Melkers, J. (2020). Lurking and participation in the virtual classroom: The effects of gender, race, and age among graduate students in computer science. Computers \& Education, 151, 103854.

Sadler, T. D. (2009). Situated learning in science education: socio-scientific issues as contexts for practice. Studies in Science Education, 45(1), 1-42.

Salomon, G. (2000). E-moderating the key to teaching and learning online. Kogan Page.

Salta, K., \& Koulougliotis, D. (2020). Domain specificity of motivation: Chemistry and physics learning among undergraduate students of three academic majors. International Journal of Science Education, 42(2), 253-270.

Shu, H., \& Gu, X. (2018). Determining the differences between online and face-to-face student-group interactions in a blended learning course. The Internet and Higher Education, 39, 13-21.

Sun, J. C. Y., \& Rueda, R. (2012). Situational interest, computer self-efficacy and self-regulation: Their impact on student engagement in distance education. British Journal of Educational Technology, 43(2), 191-204.

Swan, K. (2001). Virtual interaction: Design factors affecting student satisfaction and perceived learning in asynchronous online courses. Distance Education, 22(2), 306-331.

Swan, K., \& Shea, P. (2005). The development of virtual learning communities. In S. R. Hiltz \& R. Goldman (Eds.), Asynchronous Learning Networks: The Research Frontier. (pp. 239-260). Hampton Press.

UNESCO. (2020). Education: From disruption to recovery. https://en.unesco.org/covid19/educationr esponse. Accessed 24 April 2021.

United Nations. (2020). Policy brief: Education during COVID-19 and beyond. New York. https://unsdg.un. org/sites/default/files/2020-08/sg_policy_brief_covid-19_and_education_august_2020.pdf. Accessed 24 April 2021.

Vygotsky, L. S. (1986). Thought and language. MIT Press.

Wagner, E. D. (1994). In support of a functional definition of interaction. The American Journal of Distance Education, 8(2), 6-29.

Wang, C. H., Shannon, D. M., \& Ross, M. E. (2013). Students' characteristics, self-regulated learning, technology self-efficacy, and course outcomes in online learning. Distance Education, 34(3), 302-323.

Webster, J., \& Hackley, P. (1997). Teaching effectiveness in technology-mediated distance learning. Academy of Management Journal, 40(6), 1282-1309.

Wu, D., \& Hiltz, S. R. (2004). Predicting learning from asynchronous online discussions. Journal of Asynchronous Learning Networks, 8(2), 139-152.

Zhao, C. M., \& Kuh, G. D. (2004). Adding value: Learning communities and student engagement. Research in Higher Education, 45(2), 115-138.

Zimmerman, B. J. (1990). Self-regulated learning and academic achievement: An overview. Educational Psychologist, 25(1), 3-17.

Publisher's Note Springer Nature remains neutral with regard to jurisdictional claims in published maps and institutional affiliations. 